\title{
Preparação e Caracterização de Estruturas Porosas de Poli(3-hidroxibutirato)
}

\author{
Márcia S. Sader \\ Instituto de Macromoléculas Professora Eloísa Mano, UFRJ \\ Programa de Engenharia Metalúrgica e de Materiais, COPPE, UFRJ \\ Marysilvia Ferreira \\ Programa de Engenharia Metalúrgica e de Materiais, COPPE, UFRJ \\ Marcos L. Dias \\ Instituto de Macromoléculas Professora Eloisa Mano, UFRJ
}

\begin{abstract}
Resumo: A aplicação de estruturas tridimensionais bio-reabsorvíveis como suporte temporário na engenharia de tecidos tem crescido nos últimos anos. Neste estudo, estruturas porosas de poli(3-hidroxibutirato) $(\mathrm{P}(3 \mathrm{HB})$ ) foram preparadas pelo método de vazamento e lixiviação de partículas. As amostras foram obtidas pela adição de cloreto de sódio em concentrações de 50, 60, 70, 80 e $90 \%$ p/p, a uma solução de P(3HB) em clorofórmio. O tamanho das partículas de sal foi controlado nas faixas de 38-53, 53-75 e 75-150 $\mu \mathrm{m}$. As propriedades térmicas das matrizes poliméricas foram estudadas via calorimetria diferencial de varredura (DSC) e análise termogravimétrica (TGA). A morfologia das amostras foi observada por microscopia eletrônica de varredura $(\mathrm{MEV})$, onde se constatou a formação de estruturas assimétricas para concentrações de sal de 50,60 e eventualmente $70 \%$. Os tamanhos dos poros obtidos apresentaram dependência somente com a fração em peso inicial e com o tamanho da partícula do sal empregado. Análises de difração de raios X indicaram que o tipo de sal, a concentração e a granulometria não influenciam as características cristalinas do polímero na estrutura porosa. Pelo teste de bioatividade "in vitro" foi constatada a formação espontânea de uma camada de fosfato de cálcio sobre a superfície das estruturas porosas.
\end{abstract}

Palavras-chave: Poli(3-hidroxibutirato), polímero bio-reabsorvivel, engenharia de tecidos, testes "in vitro".

\section{Preparation and Characterization of Poly(3-hydroxybutyrate) Porous Structures}

Abstract: Three-dimensional polymeric scaffolds have been widely employed as support in tissue engineering to reconstruct damaged or lost tissue. In this study porous structures were obtained using $\mathrm{P}(3 \mathrm{HB})$ solution with five concentrations of sieved sodium chloride 50, 60, 70, 80 and $90 \mathrm{wt} \%$, with particles size in the range of $75-150,53-75$ and $38-53 \mu \mathrm{m}$. Thermal properties of the samples were investigated by differential scanning calorimetry and thermo gravimetric analysis, while the morphology was observed by scanning electron microscopy. Asymmetric porous structures were formed for salt concentrations of 50,60 and in some cases $70 \mathrm{wt} \%$. Additionally, porosity increased as the salt weight fraction was increased and pore diameter increased as the salt particle size increased. X-Ray diffraction analysis showed that salt concentration and granulometry did not influence the crystalline characteristics of the porous matrices when compared with the dense polymer film obtained by casting of a solution without salt. The scaffolds promote the spontaneous deposition of a calcium phosphate layer, indicating bioactivity.

Keywords: Poly(3-hydroxybutyrate), bioresorbable polymer, tissue engineer, scaffolds, "in vitro" tests.

\section{Introdução}

O aumento da expectativa e da qualidade de vida junto com os avanços da medicina atual tem possibilitado o desenvolvimento de novos materiais a serem utilizados como dispositivos temporários ou permanentes para implantes no corpo humano ${ }^{[1]}$.
Os polímeros têm sido a classe de materiais mais versátil na medicina, em biotecnologia e nas indústrias de cosméticos e alimentos. Eles podem ser utilizados como biomateriais, podendo ser sintetizados com propriedades químicas, físicas, interfaciais e biomiméticas específicas para cada tipo de aplicação ${ }^{[2]}$. Podem ser usados, por exemplo, como implantes permanentes para reparar, restaurar

Autor para correspondência: Marcos L. Dias, Instituto de Macromoléculas Professora Eloisa Mano, UFRJ, Centro de Tecnologia, Caixa Postal 68525, CEP: 21945-970, Rio de Janeiro, RJ. E-mail: mldias@ima.ufrj.br. 
ou reconstituir tecidos, em aplicações de substituição total ou parcial de órgãos ou tecidos danificados, e em composições biodegradáveis adequadas para substituição temporária.

A crescente escassez de órgãos e tecidos para transplantes motivou o estudo de matrizes poliméricas que induzissem a regeneração tridimensional de tecidos danificados por doenças e traumas ou mesmo perdidos. O tecido pode ser reconstituído a partir de células transplantadas, o que envolve a sua expansão "in vitro" e "in vivo". Os implantes autólogos são os mais recomendáveis, uma vez que as células, sendo do próprio paciente, minimizam o problema de transmissão de doenças e rejeição ${ }^{[3]}$. Os requisitos físicos e químicos para dispositivos usados como substitutos temporários em engenharia de tecidos são biocompatibilidade, biodegradabilidade, resistência mecânica, porosidade com interconexão de poros e distribuição uniforme de poros ${ }^{1}$. Novos polímeros que tenham como característica a biodegradabilidade, a biocompatibilidade e a bio-reabsorção são de grande interesse nessa área de bioengenharia tecidual, uma vez que o número de transplantes de órgãos é cada vez mais limitado.

O potencial de utilização de um polímero natural biodegradável e bio-reabsorvível dentro do corpo humano foi o objetivo do presente estudo, que envolveu a obtenção e caracterização de estruturas porosas com possível aplicação em engenharia de tecidos.

O poli(3-hidroxibutirato) ou $\mathrm{P}(3 \mathrm{HB})$ é um poliéster alifático natural obtido por fermentação bacteriana utilizando fontes de carbono renováveis. A sacarose da cana de açúcar tem sido utilizada como fonte de carbono para a fermentação aeróbica por bactérias Alcaligenes Eutrophus ${ }^{[4]}$ para a obtenção do polímero por indústria nacional, o que torna seu uso vantajoso.

$\mathrm{O} \mathrm{P}(3 \mathrm{HB})$ pertence a uma classe de poliésteres biodegradáveis e biocompatíveis com grande perspectivas em aplicações na bioengenharia tecidual ${ }^{[5]}$. Neste trabalho, estruturas porosas de $\mathrm{P}(3 \mathrm{HB})$ foram preparadas a partir de soluções poliméricas contendo cloreto de sódio, pelo método de vazamento e lixiviação, onde o tamanho das partículas de sal foi controlado. A influência do sal nas propriedades térmicas, morfologia das matrizes poliméricas porosas e estrutura cristalina foram investigadas. A bioatividade das estruturas porosas foi também avaliada pela observação da capacidade de formação de uma camada de fosfato de cálcio sobre suas superfícies.

\section{Experimental}

\section{Preparação das estruturas porosas}

$\mathrm{O}$ P(3HB) (Copersucar) foi dissolvido por extração em aparelhagem Soxhlet a quente com clorofórmio $\left(\mathrm{CHCl}_{3}\right)$ a concentração final ajustada para $10 \%$. Partículas secas de cloreto de sódio $(\mathrm{NaCl})$ nas faixas granulométricas de 75$150,53-75$ e $38-53 \mu \mathrm{m}$ foram adicionadas à solução polimérica e dispersadas sob agitação magnética imediatamente antes do vazamento. Foram utilizadas composições com 50, 607080 e 90\% (p/p) de sal com relação à massa de polímero. As soluções foram vazadas em placa de Petri e mantidas sob fluxo contínuo de nitrogênio para evaporação controlada do solvente. Uma vez removido o solvente, as amostras foram imersas em água destilada por $48 \mathrm{~h}$ para a dissolução das partículas de sal, secas à temperatura ambiente e submetidas a vácuo para remoção de moléculas de solvente residuais.

\section{Análise termogravimétrica (TGA)}

A análise de TGA da estrutura porosa obtida com $90 \%$ de cloreto de sódio com faixa granulométrica de $38-53 \mu \mathrm{m}$ foi conduzida a uma taxa de aquecimento de $10{ }^{\circ} \mathrm{C} / \mathrm{min}$ em atmosfera de nitrogênio até $700{ }^{\circ} \mathrm{C}$, utilizando-se $5 \mathrm{mg}$ de massa da amostra. A análise foi realizada em um analisador termogravimétrico (TGA) modelo PYRIS.1, Perkin Elmer. A análise permitiu identificar também possíveis resíduos do sal utilizado na obtenção das amostras porosas.

\section{Calorimetria diferencial de varredura (DSC)}

As transições térmicas que ocorrem durante o aquecimento e resfriamento da amostra foram obtidas através das curvas de DSC. No primeiro ciclo de aquecimento a amostra foi aquecida até $200^{\circ} \mathrm{C}$ sob atmosfera de nitrogênio numa taxa de $10^{\circ} \mathrm{C} / \mathrm{min}$, seguido de resfriamento à $200^{\circ} \mathrm{C} / \mathrm{min}$ (quenching). Em um segundo ciclo de aquecimento, a amostra foi aquecida de -20 a $200{ }^{\circ} \mathrm{C}$ numa taxa de $10{ }^{\circ} \mathrm{C} / \mathrm{min}$, seguida de resfriamento na mesma taxa. Utilizou-se um calorímetro diferencial de varredura Perkin-Elmer, modelo DSC-7.

\section{Microscopia eletrônica de varredura (MEV)}

Para avaliação da seção transversal, as amostras foram fraturadas após imersão em nitrogênio líquido e recobertas com uma fina camada de ouro para observação por MEV. As micrografias foram obtidas a uma voltagem de $15 \mathrm{KV}$. As análises foram realizadas em microscópio eletrônico ZEISS, modelo DSM 940A.

\section{Difração de raios-X}

$\mathrm{A}$ análise de difração de raios- $\mathrm{X}$ foi realizada em amostras com dimensões $2 \times 2$ cmutilizando equipamento Rigaku, modelo Miniflex com radiação $\mathrm{CuK} \alpha(\lambda=1,5418 \AA), 30 \mathrm{KV}$ e ângulo de varredura (20) de 2 a $60^{\circ}$. As distâncias interplanares características de cada material foram identificadas.

\section{Teste de bioatividade e citotoxicidade}

O teste de bioatividade foi conduzido em experimento "in vitro", onde se avaliou a capacidade do material em formar uma camada de fosfato de cálcio sobre a superfície. A amostra foi imersa em uma solução acelular, similar ao fluido corpóreo, sorological body fluid (SBF), a $37{ }^{\circ} \mathrm{C} \mathrm{em} \mathrm{pH} \mathrm{7,4.}$ Nesta solução, as concentrações iônicas são bem próximas ao plasma do sangue humano (Tabela 1). A formação de precipitado de fosfato de cálcio sobre as superfícies densa e porosas foi avaliada por MEV.

O teste de citotoxicidade (método de difusão sobre camada de ágar) foi realizado em amostras de $\mathrm{P}(3 \mathrm{HB})$ obtidas com 
Tabela 1. Concentração dos íons no plasma sanguíneo e na solução de SBF.

\begin{tabular}{lcc}
\hline \multicolumn{3}{c}{ Concentrações iônicas $(\mathbf{m M})$} \\
\hline \multicolumn{1}{c}{ Ions } & Plasma sanguíneo & SBF \\
\hline $\mathrm{Na}^{+}$ & 142 & 142 \\
$\mathrm{~K}^{+}$ & 5.0 & 5.0 \\
$\mathrm{Mg}^{2}$ & 1.5 & 1.5 \\
$\mathrm{Ca}^{2+}$ & 2.5 & 2.5 \\
$\mathrm{Cl}^{-}$ & 103 & 147 \\
$\mathrm{HCO}_{3}^{-}$ & 27 & 4.2 \\
$\mathrm{HPO}_{4}^{2-}$ & 1.0 & 1.0 \\
$\mathrm{SO}_{4}^{2-}$ & 0.5 & 0.5 \\
\hline
\end{tabular}

$80 \%$ de $\mathrm{NaCl}(53-75 \mu \mathrm{m})$, com dimensões de $10 \times 10 \mathrm{~mm}$. O teste "in vitro" consistiu em plaquear $3 \times 10^{5}$ células / $\mathrm{mL}$ de uma suspensão celular (linhagem NCTC clone 929 - BCRJ $\mathrm{n}^{\circ}$ CR 107 - ATCC CCL1 ) sobre uma placa de Petri de 60 $\mathrm{mm}$ contendo meio de cultura em $\mathrm{pH}$ 7,4. Incubou-se por 48 horas a $37^{\circ} \mathrm{C} \mathrm{em}$ atmosfera contendo $5 \% \mathrm{CO}_{2}$. Após este período, formou-se uma monocamada celular sobre a qual se despeja uma fina camada de ágar nutritivo. Colocou-se a placa por 4 minutos a $4{ }^{\circ} \mathrm{C}$ para endurecer o ágar e adiciona-se a amostra de área ou massa conhecida no centro da placa. Incubou-se por mais 24 horas a $37^{\circ} \mathrm{C}$ em atmosfera de $5 \% \mathrm{CO}_{2}$. Este teste é sugerido pelo Ministério da Saúde ${ }^{[6]}$. Foram realizados testes em triplicatas, em paralelo com um controle positivo (papel de antibiograma embebido em solução de azida sódica $20 \%$ em tampão de fosfato isotônico e $\mathrm{pH}$ neutro PBS), um controle negativo (papel de antibiograma) e um controle sem material para avaliar erros na metodologia ${ }^{[7]}$.

\section{Resultados e Discussão}

\section{Propriedades térmicas das estruturas porosas}

O estudo da degradação térmica da estrutura porosa de $\mathrm{P}(3 \mathrm{HB})$ obtido por análise termogravimétrica foi realizado objetivando detectar a presença de resíduo salino na amostra. A curva de degradação térmica da amostra com $90 \%$ de sal com granulometria de $38-53 \mu \mathrm{m}$ pode ser visualizada na Figura 1. Observa-se que a decomposição do material ocorreu em apenas um único estágio, com velocidade de decomposição máxima ocorrendo em $274^{\circ} \mathrm{C}$, indicando a pureza do material. A temperatura inicial de decomposição, $\mathrm{T}_{\mathrm{i}}$, onde tem início o processo de variação de massa da amostra (on set) foi de $262{ }^{\circ} \mathrm{C}$, enquanto que a temperatura final de decomposição, $\mathrm{T}_{f}$, que indica o término do processo se deu em torno de $290{ }^{\circ} \mathrm{C}$. Observou-se uma massa residual de $1,1 \%$ após o término do processo, o que indica a presença de resíduo salino, sugerindo que uma parte muito pequena do sal não pôde ser removida após o processo de lixívia. Este resíduo não foi observado para a análise de TGA de filme denso (obtido sem adição de sal). Adicionalmente, o mesmo filme

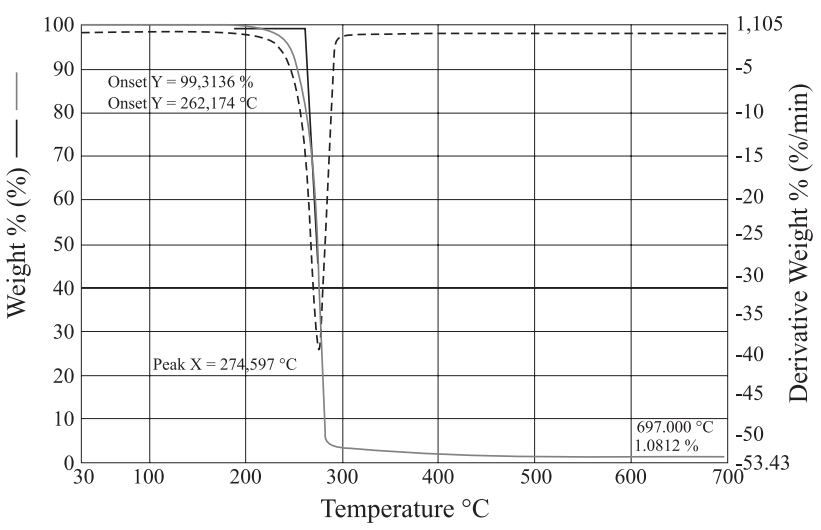

Figura 1. Curva de decomposição térmica da amostra preparada com $90 \%$ de cloreto de sódio $(38-53 \mu \mathrm{m})$.

denso apresenta taxa de decomposição máxima em temperatura superior à das estruturas porosas, sugerindo que a porosidade acelera o processo de degradação térmica.

A influência da concentração e da granulometria do sal nas transições térmicas e na cristalinidade das estruturas porosas foi verificada por DSC. A Tabela 2 apresenta os resultados de temperatura de transição vítrea $\left(\mathrm{T}_{\mathrm{g}}\right)$, as temperaturas de cristalização que ocorrem durante o aquecimento $\left(\mathrm{T}_{\text {ch }}\right) \mathrm{e}$ o resfriamento $\left(\mathrm{T}_{\mathrm{cc}}\right)$, e a temperatura de fusão $\left(\mathrm{T}_{\mathrm{m}}\right)$ dos scaffolds obtidos.

A Figura 2 mostra as curvas térmicas do filme denso sem a presença de sal. O primeiro ciclo de aquecimento apresenta dois picos endotérmicos de fusão $\left(153\right.$ e $\left.172{ }^{\circ} \mathrm{C}\right)$, caracterizando a presença de duas populações de cristais com tamanhos distintos. Com a fusão seguida de resfriamento brusco $\left(200^{\circ} \mathrm{C} / \mathrm{min}\right)$, espera-se obter um polímero altamente amorfo, uma vez que as cadeias não terão chance de se organizar e formar as regiões cristalinas, apagando-se assim a história térmica da amostra. No segundo ciclo de aquecimento, as cadeias do polímero amorfo adquirem mobilidade ao alcançar a $\mathrm{T}_{\mathrm{g}}\left(-1^{\circ} \mathrm{C}\right)$. À medida que a temperatura

Tabela 2. Transições térmicas das estruturas porosas de $\mathrm{P}(3 \mathrm{HB})$.

\begin{tabular}{cccccc}
\hline NaCl & \multicolumn{5}{c}{ Temperatura de transição $\left({ }^{\circ} \mathbf{C}\right)$} \\
\hline Granulometria & $\%$ & $\mathbf{T}_{\mathbf{m}(\mathbf{a})}$ & $\mathbf{T}_{\mathbf{c h}(\mathbf{b})}$ & $\mathbf{T}_{\mathbf{c c} \odot}$ & $\mathbf{T}_{\mathbf{g}(\mathrm{d})}$ \\
\hline \multirow{2}{*}{ 38-53 } & 50 & 173 & 37 & 67 & -1 \\
& 70 & 173 & 37 & 64 & -1 \\
& 90 & 173 & 39 & 69 & -1 \\
\hline \multirow{3}{*}{$53-75$} & 50 & 170 & 37 & 75 & -1 \\
& 70 & 172 & 35 & 80 & -1 \\
& 90 & 173 & 43 & 48 & -4 \\
\hline \multirow{2}{*}{$75-150$} & 70 & 175 & 35 & 58 & -1 \\
& 90 & 174 & 39 & 42 & -4 \\
\hline
\end{tabular}

a) obtidas no primeiro aquecimento a $10^{\circ} \mathrm{C}$

b) obtidas no segundo aquecimento a $10^{\circ} \mathrm{C} / \mathrm{min}$ após têmpera do fundido. c) obtidas no resfriamento a $10^{\circ} \mathrm{C} / \mathrm{min}$ a partir do fundido. 


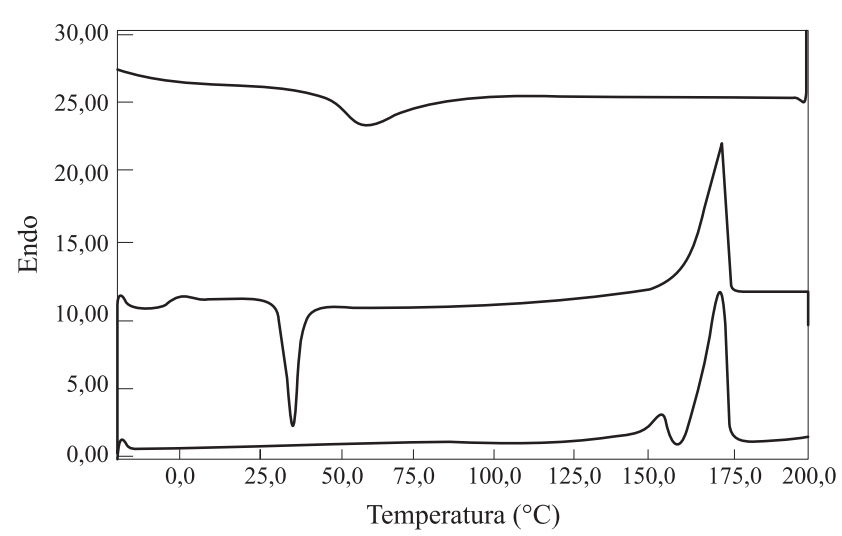

Figura 2. Curvas térmicas do filme denso de $\mathrm{P}(3 \mathrm{HB})$.

aumenta as cadeias começam novamente a se organizar formando regiões cristalinas $\left(\mathrm{T}_{\mathrm{ch}}=35,7^{\circ} \mathrm{C}\right)$. Continuando o aquecimento, os cristais formados sofrem fusão e o pico endotérmico relativo à $\mathrm{T}_{\mathrm{m}}$ aparece em $173^{\circ} \mathrm{C}$. Pode-se observar um alargamento do pico de fusão, indicando uma maior distribuição de tamanhos cristalinos. No segundo ciclo de resfriamento a $10{ }^{\circ} \mathrm{C} / \mathrm{min}$, observou-se a $\mathrm{T}_{\text {cc }}$ a $60,2{ }^{\circ} \mathrm{C}$. O filme denso apresentou maior entalpia de cristalização no reaquecimento a $10^{\circ} \mathrm{C} / \mathrm{min}$ após a têmpera, indicando a presença de maior quantidade de fase amorfa em relação as amostras porosas.

A Figura 3 mostra as curvas de DSC da estrutura porosa preparada com $90 \%$ de cloreto de sódio de granulometria de $38-53 \mu \mathrm{m}$. O primeiro ciclo de aquecimento da estrutura porosa apresentou dois picos de fusão cristalina estreitos, com valores muito próximos aos encontrados para o filme denso, indicando que não houve variação significativa no tamanho dos cristais das estruturas porosas. Na cristalização das estruturas porosas durante o reaquecimento pós-têmpera, a menor entalpia da transição em relação ao filme denso indicou que uma significativa quantidade de $\mathrm{P}(3 \mathrm{HB})$ cristalizou mesmo sob têmpera. Isto pode ter sido devido à presença de sal residual, que pode ter atuado como agente nucleante.

As amostras também apresentaram dois picos de fusão no segundo ciclo de aquecimento. Este fato sugere que, mesmo

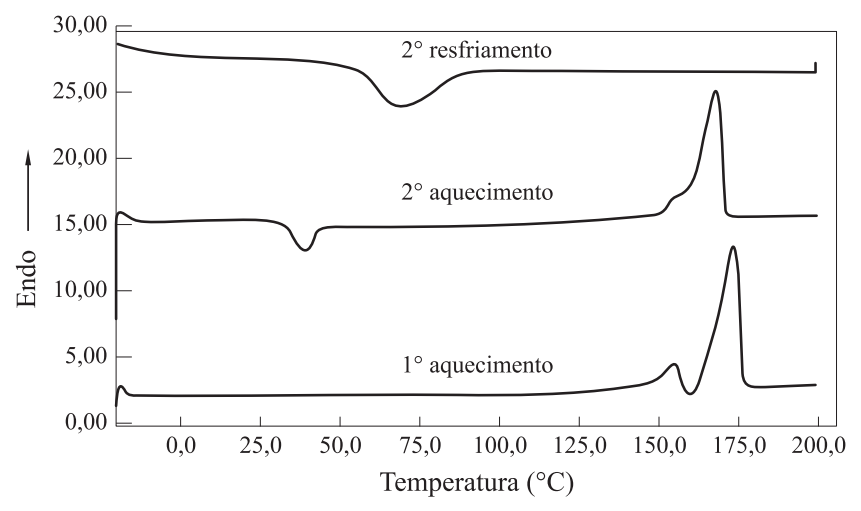

Figura 3. Curvas térmicas da estrutura porosa de $\mathrm{P}(3 \mathrm{HB})$ preparada com $90 \%$ cloreto de sódio com granulometria de $38-53 \mu \mathrm{m}$.

não tendo sido encontradas quantidades significativas de sal nas estruturas porosas, traços desse sal influenciaram a cristalização, promovendo a existência de cristais menos perfeitos ou de tamanhos muito diferentes, de menor $\mathrm{T}_{\mathrm{m}}$.

No segundo ciclo de resfriamento, a temperatura de cristalização da estrutura porosa preparada com cloreto de sódio foi superior a do filme denso, indicando uma maior velocidade de cristalização. Este comportamento constituiu-se em outra evidência do efeito da presença de sal residual, confirmado pelas análises de TGA, que estaria agindo como núcleos de cristalização, aumentado assim a velocidade de cristalização.

As temperaturas de fusão e de transição vítrea não variaram com o aumento da concentração e com a granulometria do sal, levando-se em consideração o erro experimental de $\pm 2 \%$. Em todas as amostras a $\mathrm{T}_{\mathrm{m}}$ ocorreu em torno de $173{ }^{\circ} \mathrm{C}$ e a $\mathrm{T}_{\mathrm{g}}$ em aproximadamente $-1^{\circ} \mathrm{C}$.

Não houve uma tendência nítida de aumento ou diminuição das temperaturas de cristalização no aquecimento $\left(\mathrm{T}_{\mathrm{ch}}\right) \mathrm{e}$ no resfriamento $\left(\mathrm{T}_{\mathrm{cc}}\right)$ com o aumento da concentração de sal empregado na preparação das amostras porosas.

\section{Morfologia das estruturas porosas}

A morfologia das estruturas porosas obtidas foi observada por MEV. Quando concentrações do sal nas faixas de 50, 60 e eventualmente $70 \%$ são empregadas, formam-se
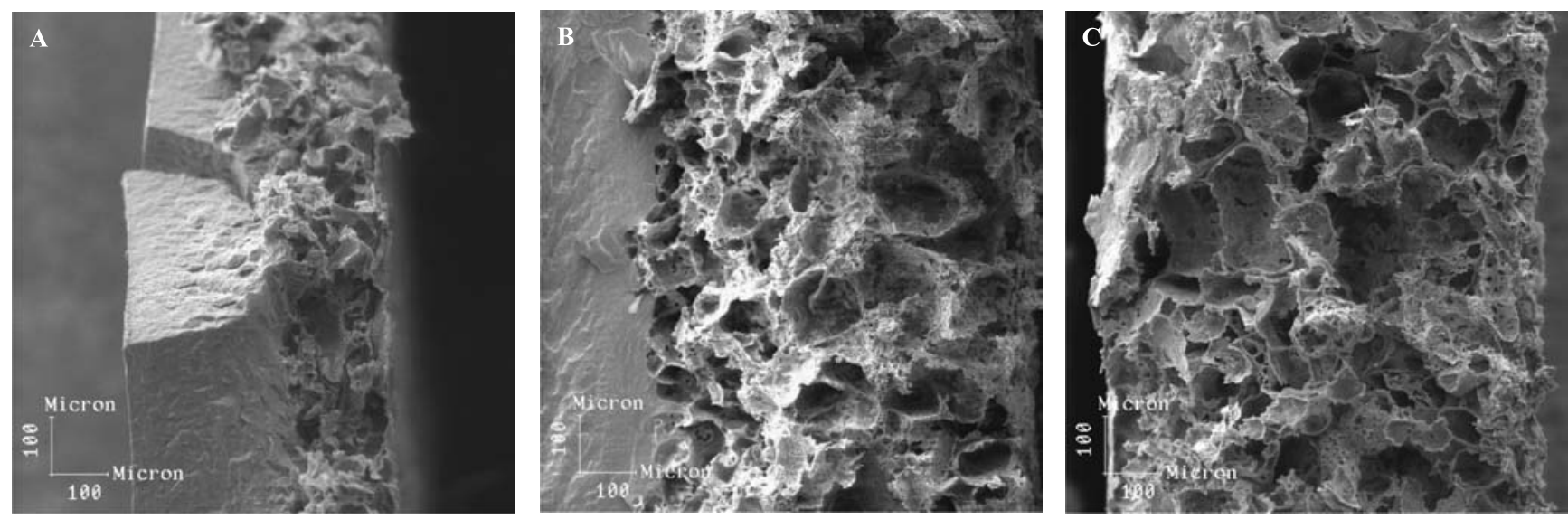

Figura 4. Micrografias da superfície de fratura criogênica das estruturas porosas de $\mathrm{P}(3 \mathrm{HB}$ ) obtidas com $50 \%$ (a), $70 \%$ (b) e $90 \%$ (c) de $\mathrm{NaCl}$ na faixa granulométrica de $75-150 \mu \mathrm{m}$. 

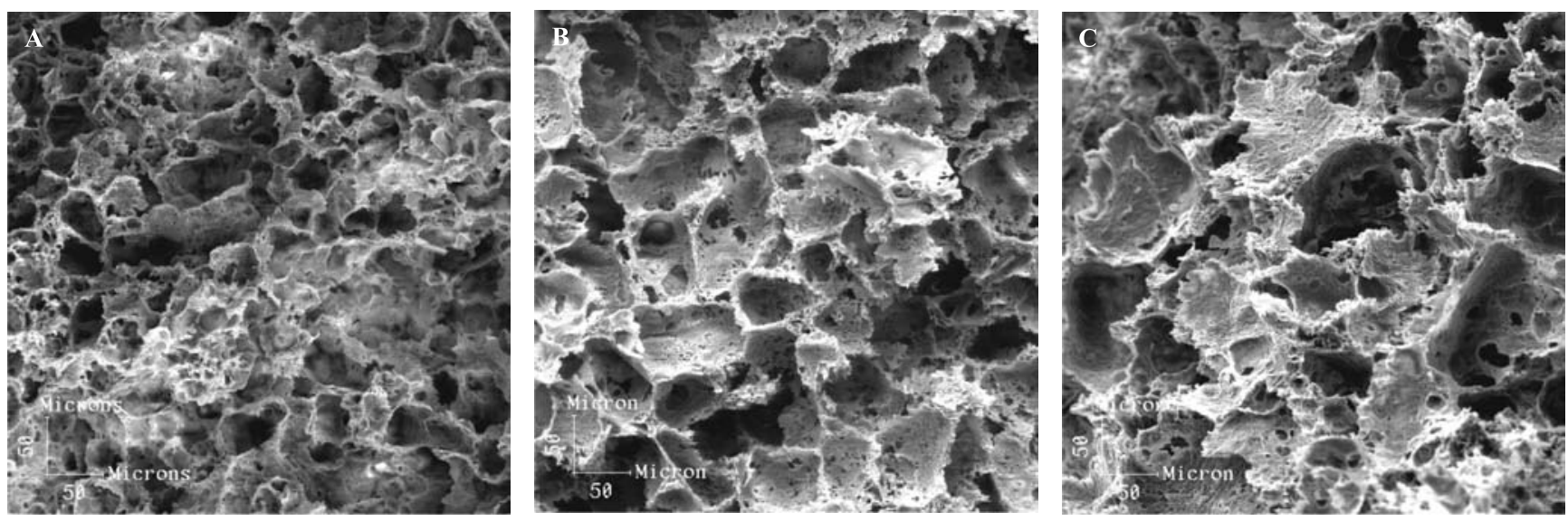

Figura 5. Micrografias da superfície de fratura criogênica das estruturas porosas de $\mathrm{P}(3 \mathrm{HB})$ nas três faixas granulométricas $38-53 \mu \mathrm{m}$ (a), 53-75 $\mu \mathrm{m}$ (b) e $75-150 \mu \mathrm{m}(\mathrm{c})$.

estruturas assimétricas com uma pele densa na superfície exposta ao ar como pode ser visto na Figura 4. Nestes casos, a quantidade de sal utilizada não foi suficiente para preencher todo o volume da solução polimérica depositada sobre o vidro, levando à decantação das partículas de sal no fundo da placa com conseqüente formação da estrutura assimétrica. Pode-se notar adicionalmente que, quanto maior a quantidade de sal, maior a quantidade de poros formados. O tamanho dos poros aumentou com o aumento do tamanho da partícula de sal, como pode ser visto de forma nítida nas micrografias das superfícies de fratura criogênica mostradas na Figura 5.

A Figura 6 mostra os difratogramas de raios-X das estruturas porosas preparadas com 60,70 e $80 \%$ de $\mathrm{NaCl}$ na faixa granulométrica de $53-75 \mu \mathrm{m}$. Os resultados indicam que a concentração e o tamanho de partícula de sal na etapa de preparação da estrutura sólida porosa não influenciaram a estrutura cristalina, considerando que os valores das distâncias interplanares e a largura das reflexões cristalinas foram similares as encontradas para o filme denso do polímero. Não foram observadas reflexões correspondentes aos cristais do cloreto de sódio utilizado na preparação das estruturas porosas, indicando que os resíduos salinos estão em teor inferior

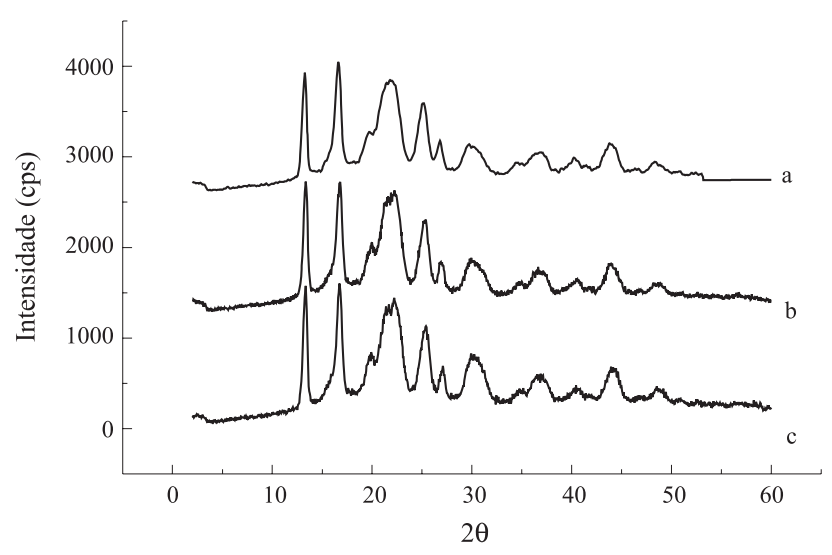

Figura 6. Difratogramas de raios- $\mathrm{X}$ das estruturas porosas de $\mathrm{P}(3 \mathrm{HB})$ obtidas com $80 \%$ (a), $70 \%$ (b) e $60 \%$ (c) de $\mathrm{NaCl}$ na faixa granulométrica de 53 - $75 \mu \mathrm{m}$. ao limite de detecção do difratômetro, uma vez que foi detectada a presença de $\mathrm{NaCl}$ na termogravimetria.

\section{Bioatividade}

Segundo alguns autores ${ }^{[8,9]}$, o requisito essencial para um material artificial exibir bioatividade é a sua capacidade de formação de uma camada de apatita carbonatada "in vivo", tipo osso, sobre a sua superfície. A ósseo-integração é um processo complexo. Muitos testes "in vitro" têm sido feitos para reproduzir o processo biológico natural ${ }^{[10]}$. Este processo de precipitação de fosfatos de cálcio simula aquele que ocorre no fluído corpóreo (processo biomimético).

$\mathrm{O}$ teste de bioatividade consiste em verificar a formação de uma camada de fosfato de cálcio depositada sobre a superfície do material quando este entra em contato com uma solução acelular com concentrações iônicas que simulem o plasma do sangue humano ${ }^{[11]}$. A Figura 7 apresenta as micrografias das superfícies do $\mathrm{P}(3 \mathrm{HB})$ puro (filme denso) e das estruturas porosas obtidas com $80 \%$ de cloreto de sódio na faixa granulométrica de $75-150 \mu \mathrm{m}$ (x200), após exposição à solução simulada do fluído corpóreo.

Pode-se observar a formação de uma camada depositada sobre a superfície do filme denso e da estrutura porosa logo nos primeiros 14 dias. Com o aumento do tempo de imersão em SBF, uma camada mais homogênea foi formada. Pode-se notar que a superfície mais porosa propiciou a precipitação dos fosfatos de cálcio nestes sítios (poros), levando a um revestimento mais denso.

\section{Citotoxicidade}

Culturas de células “in vitro' podem avaliar o potencial de citotoxicidade de biomateriais. Este procedimento indica a capacidade intrínseca do material de promover alteração metabólica de células em cultura, podendo levar ou não à morte celular ${ }^{[7]}$.

A leitura dos resultados foi feita macro e microscopicamente no microscópio ótico de luz invertida. Macroscopicamente, observa-se o "halo de morte", e microscopicamente, é possível observar se a mortalidade foi acompanhada de lise celular. O índice de resposta é calculado pela razão entre o índice de zona e o índice de lise (percentual de células lisadas): 

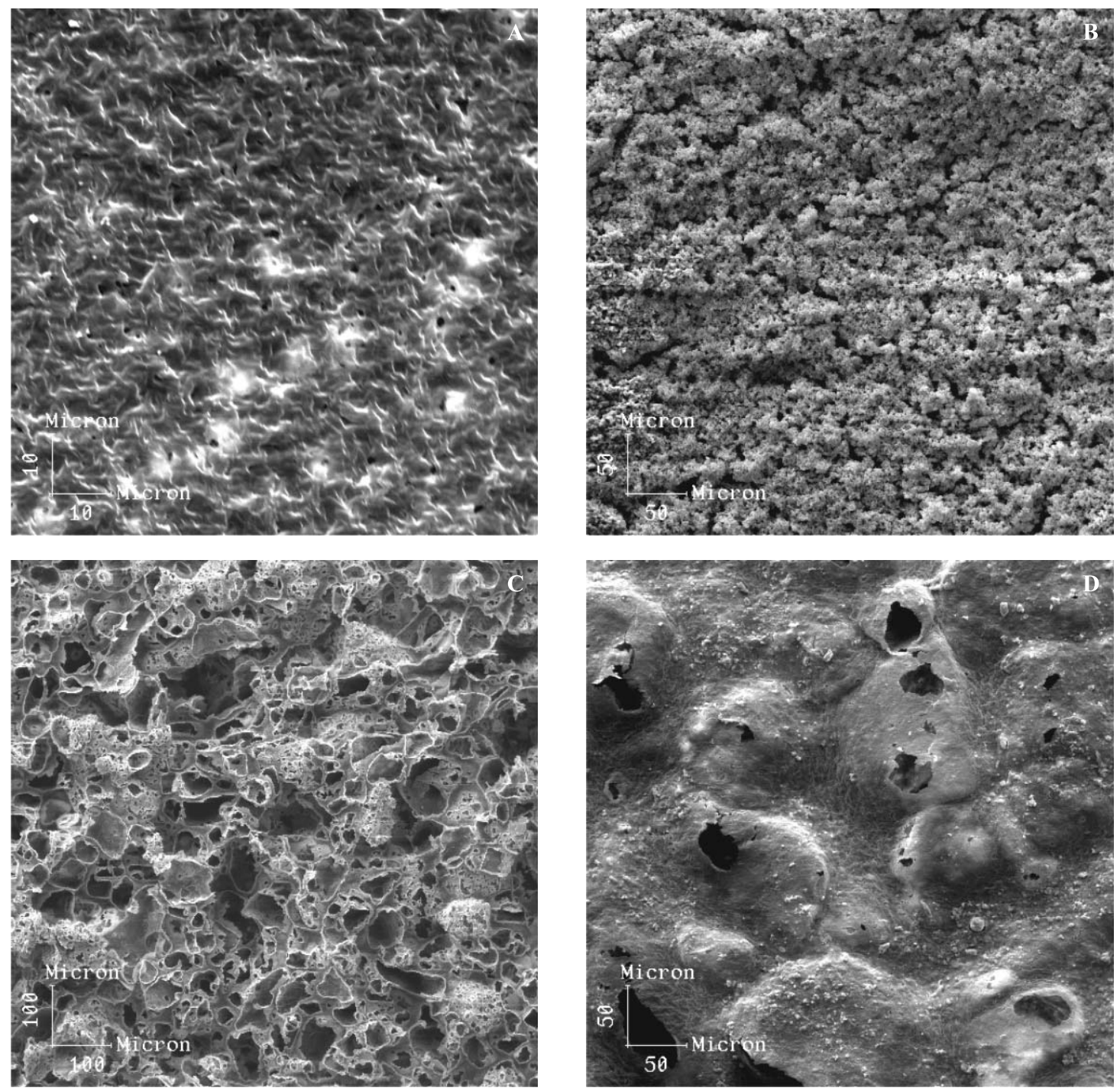

Figura 7. Micrografias das superfícies da estrutura densa antes (a) e após (b) 14 dias de exposição à solução simulada do fluído corpóreo e da estrutura porosa de $\mathrm{P}(3 \mathrm{HB})$ obtidas com $80 \%$ de cloreto de sódio na faixa granulométrica de 75 - $150 \mu \mathrm{m}$ antes(c) e após (d) 14 dias de exposição à mesma solução.

Índice de resposta (IR) = índice de zona (IZ) / índice de lise (IL)

onde:

IZ - índice de zona, relacionado à área não corada (halo de células mortas)

$\mathrm{IL}$ - índice de lise, correspondente à porcentagem de células degeneradas

A Tabela 3 apresenta a classificação do índice de citotoxicidade pelo lise celular.

Tabela 3. Classificação do índice de citotoxicidade pelo lise celular.

\begin{tabular}{ll}
\hline \multicolumn{1}{c}{ Índice de Zona (IZ) } & Índice de Lise (IL) \\
\hline 0. nenhuma zona sob e ao redor da amostra & 0. nenhuma lise \\
1. zona limitada sob a amostra & 1. menos que $20 \%$ \\
2. zona não maior que $2 \mathrm{~mm}$ & 2. menos que $40 \%$ \\
3. zona maior que $2 \mathrm{~mm}$ e menor que $10 \mathrm{~mm}$ & 3. menos que $60 \%$ \\
4. zona entre $10-20 \mathrm{~mm}$ & 4. menos que $80 \%$ \\
5. zona maior que $20 \mathrm{~mm}$ & 5. mais que $80 \%$ \\
\hline
\end{tabular}

A zona ao redor do scaffold mostrou células vivas. Isto sugere que o material não produz qualquer tipo de reação às células. As amostras não apresentaram zona de lise e nenhuma zona limitada sob e ao redor da amostra. Considerando os parâmetros macroscópicos e microscópicos, nenhum halo de morte e lise celular foi observado para a amostra testada. Por apresentar comportamento igual ao controle negativo, a amostra foi aprovada, não apresentando nenhum grau de citotoxicidade.

\section{Conclusões}

Estruturas porosas de $\mathrm{P}(3 \mathrm{HB})$ com distribuição homogênea de poros e porosidade controlada podem ser preparadas por vazamento de soluções poliméricas em $\mathrm{CHCl}_{3}$ contendo $\mathrm{NaCl}$ e lixiviação. Não houve tendências nítidas no aumento ou diminuição das temperaturas de transição térmica do polímero nas estruturas porosas quando obtidas com diversas concentrações de sal, nas três faixas granulométricas empregadas. A análise de TGA indicou a presença de pequeno resíduo salino após o processo de lixiviação, mostrando 
que a lixívia com água promoveu a remoção quase total do sal. Estruturas porosas assimétricas são formadas para concentrações de sal de 50,60 e eventualmente 70\%. À medida que o tamanho de partícula do sal aumenta, o tamanho do poro também aumenta. As estruturas porosas de $\mathrm{P}(3 \mathrm{HB})$ promoveram a deposição espontânea de fosfato de cálcio, indicativo de bioatividade e não foi constatado indícios de citotoxicidade dessas estruturas, o que permite concluir que poderiam ser aplicáveis como scaffolds em engenharia de tecidos.

\section{Agradecimentos}

Os autores agradecem a COPERSUCAR, o Banco de Células do Rio de Janeiro (BCRJ), onde se realizaram os testes "in vitro", e o suporte financeiro dado pelo CNPq, pela FAPERJ e pela FUJB.

\section{Referências Bibliográficas}

1. Tabata, Y. - Drug Discovery Today, 6, p. 483, (2001).

2. Regí, M. V. Anales de Química, p. 93: S6 - S14, (1997).

3. Hutmacher, D. W. - Biomaterials, 21, p. 2529, (2000).

4. "Obtenção de plástico biodegradável a partir de cana de açucar", Copersucar, 1995.

5. Reddy, C. S. K.; Ghai, R.; Kalia V. C. - “ Polyhydroxyalkanoates: an overview", Bioresource Technology, 87, p.137 (2003).
6. Diário Oficial da União, Segunda-feira, seção I, p.229, 7 de janeiro (1991).

7. Lawrence, W-H - "Toxicity of Plastics used in medical practice I", Journal of Pharmaceutical Sciences 52, p.958 (1973).

8. Kokubo, T.; Kim, H.; Kawashita, M. \& Nakamura, T. "What kinds of materials exhibit bone - bonding", in Bone Engineering, p190, EM Squared Incorporated, Toronto, Canada, 2001,

9. Ducheyne, P. \& Qiu, Q. - "Bioactive ceramics: the effect of surface reactivity on bone formation and bone cell function”, Biomaterials, 20, p. 2287 (1999).

10. Miyaji, F.; Handa, S.; Kokubo T. \& Nakamura, T. - “Apatite Formation on Polymers by Biomimetic Process Using Sodium Silicate Solution”, in Proceedings of the 10th International Symposium on Ceramics in Medicine, p.7, Japan, october (1997).

11. Kim, H. M.; Miyazaki, T.; Kokubo, T. \& Nakamura, T."Revised simulated body fluid", in Proceedings of the $13^{\text {th }}$ Int. Symp. On Ceramics in Medicine, p 47, Bologna -Italy, (2001).

Enviado: 26/01/04

Reenviado: $17 / 11 / 05$

Aprovado: 24/11/05 